\title{
Measuring scales used for assessment of patients with traumatic brain injury: multicenter studies
}

This article was published in the following Dove Press journal:

Patient Preference and Adherence

30 June 2015

Number of times this article has been viewed

\section{Robert Ślusarz' \\ Renata Jabłońska' \\ Agnieszka Królikowska' \\ Beata Haor' \\ Ewa Barczykowska ${ }^{2}$ \\ Monika Biercewicz ${ }^{3}$ \\ Mariola Głowacka ${ }^{2}$ \\ Justyna Szrajda ${ }^{4}$}

'Neurological and Neurosurgical Nursing Department, ${ }^{2}$ Nursing Department, ${ }^{3} \mathrm{Clinic}$ of Geriatrics, ${ }^{4}$ Department of Hygiene and Epidemiology, Collegium Medicum, Nicolaus Copernicus University, Torun, Poland
Correspondence: Robert Ślusarz Neurological and Neurosurgical Nursing Department, Collegium Medicum, Nicolaus Copernicus University, ul Techników 3, 85-094 Bydgoszcz, Poland Tel +485I 6856939

Email zpielnin@cm.umk.pl
Background: Application of adequate numeric scales is essential for assessment of a patient's condition. The scales most commonly used by the therapeutic team for assessment of a patient with traumatic brain injury (TBI) include deficit scales, functional scales, and scales assessing quality of life. The purpose of this study was to establish the relationships between the particular scales used for assessment of patients with TBI.

Methods: This multicenter study included 159 patients with TBI. The direct observation technique was used. Two measurements were made (at hospital admission and discharge) using standardized assessment scales, ie, the Glasgow Coma Scale (GCS), the Functional Capacity Scale (FCS), the Functional Index "Repty" (FIR), and the Glasgow Outcome Scale.

Results: Patients with mild impairment of consciousness were most numerous in the examined group at both admission and discharge, ie, 118 (78.8\%) and 134 patients (89.3\%), respectively. The mean score for functional capacity measured with the FCS was 34.41 points $(71.7 \%)$ on the day of admission and 41.87 points $(87.2 \%)$ on the day of discharge from hospital. A significant correlation was found between results obtained using the GCS and results on the FIR, on both the day of admission $[R \mathrm{t}(\mathrm{n}-2)=7.612=0.530 ; P=0.00]$ and the day of discharge $[R \mathrm{t}(\mathrm{n}-2)=8.998=0.595 ; P=0.00]$. Further, a high correlation was found between the FCS and the FIR ( $r_{\mathrm{s}}=-0.854$ on day of admission and $r_{\mathrm{s}}=-0.840$ on day of discharge).

Conclusion: The majority of examined patients had mild impairment of consciousness. A moderate correlation was found between the GCS and the scales assessing activities of daily living. A high correlation was found between FCS and FIR, which may result from the similarities between the analyzed tools in the scope of their construction and application.

Keywords: head trauma, assessment tools, numeric scales

\section{Introduction}

Application of adequate numeric scales is essential for assessment of a patient's condition. In practice, this phenomenon is called clinimetrics. ${ }^{1,2}$ Scales allow objective and complex assessment of a patient's cognitive function, and facilitate the diagnostic and therapeutic process. ${ }^{3}$ Scores obtained by patients on a particular scale reflect the results of actions taken by the therapeutic team, which is important in every health care system. Therefore, the measuring tools have to be common and universal to allow assessment of both patients and their environment. With such instruments, it will be possible to determine priorities based on empiric data and health concepts. They will allow health care professionals to assess the results of their actions in terms of treatment of disease as well as the long-term functioning of the patient. ${ }^{4}$

The need for development of quantitative measuring tools and their implementation in clinical practice results from the basic consequences of a disease (as defined by the World Health Organization): damage (mental, physiological, or anatomical 
deficit or defect); impairment (decreased level of an action of an organ or system as a consequence of a damage); and disability (damage and inability to perform social roles and tasks, which results in a less favorable social position). ${ }^{1}$ Another argument in favor of using numeric rating scales is paradigm in evidence-based medicine, which allows access to extensive knowledge acquired from systematic scientific studies. $^{4}$

Injuries, including traumatic brain injuries (TBIs), may be critical health-threatening and life-threatening conditions. The annual incidence of TBI is rising and is estimated at 200-300 per 100,000 population. In Poland, 20\%-30\% of all TBIs lead to moderate or severe damage. TBI is also one of the leading causes of death in Polish males. ${ }^{5}$ There are two major types of TBI, ie, closed (resulting from an impact to the skull) and open or penetrating (from the skull being penetrated by an object). A TBI may occur as single isolated injury or in combination with various other injuries. Closed injuries usually require conservative treatment. However, patients with skull fractures may need surgery.

Clinical and functional assessment of a TBI patient is important. The scales most commonly used by the therapeutic team for assessment of a patient with TBI include deficit scales, functional scales, and scales assessing quality of life. ${ }^{1}$ The Glasgow Coma Scale (GCS) is a deficit scale widely used by anesthetists and neurosurgeons to estimate the patient's level of consciousness. The most frequently used functional scales include the modified Rankin Scale, the Katz Activities of Daily Living Scale, the Barthel Index, and the Functional Independence Measure. ${ }^{1}$ Quality of life in the physical, mental, and social domains can be assessed using the Quality of Life Index devised by Ferrans and Powers, the Short Form-36, the Sickness Impact Profile, and the Quality of Life after Brain Injury scales. ${ }^{1}$

Based on the data available in the literature, it cannot be concluded which of the measuring tools (scales) described by various authors is best. However, there is evidence that they can be all successfully applied in neuro-nursing practice. The debate continues in the literature as to the most appropriate methods for assessment and treatment of TBI patients. ${ }^{6}$

The purpose of this work was to establish the relationships between the particular scales used to assess the condition of patients with TBI. To achieve this aim, the following detailed problems were formulated:

- What is the patient's level of consciousness and what is their functional capacity on the day of admission and at discharge?
- Is there a correlation between measurements made with the GCS and the scales used for assessment of functional capacity, ie, the Functional Capacity Scale (FCS) and Functional Index "Repty" (FIR)?

- Is there a correlation between assessment of a patient's condition using the FCS and assessment using the FIR?

\section{Materials and methods Study design}

The research proposal was approved by the bioethics committee. The study included patients hospitalized on five neurosurgical wards and clinics across Poland, ie, the Neurosurgery and Neurotraumatology Ward at University Hospital no 2 in Bydgoszcz, the Clinic of Neurosurgery, Neurotraumatology and Pediatric Neurosurgery at University Hospital no 1 in Bydgoszcz, the Clinic of Neurosurgery at 10th Military Clinical Hospital with Polyclinic in Bydgoszcz, the Clinic of Neurosurgery and Pediatric Neurosurgery at Clinical Hospital no 4 in Lublin, and the Clinic of Neurosurgery at University Hospital in Wrocław. Due to significant differences in numbers of hospitalized patients between the above-mentioned wards and clinics, data from only three of them, with a comparable number of patients, were analyzed. Therefore, we included 159 patients admitted to the Clinic of Neurosurgery, Neurotraumatology and Pediatric Neurosurgery at University Hospital no 1 in Bydgoszcz (63 patients, representing $39.6 \%$ of all examined patients), Neurosurgery and Neurotraumatology Ward at University Hospital no 2 in Bydgoszcz (52 patients, 32.7\%) and the Clinic of Neurosurgery at 10th Military Clinical Hospital with Polyclinic in Bydgoszcz (44 patients, 27.7\%).

\section{Data collection}

Data were collected for patients admitted to wards/clinics with TBI and underwent conservative or surgical treatment. The patients were assessed twice by a trained neuro-nursing team, ie, on the day of admission (assessment 1) and on the day of discharge (assessment 2). The majority of the patients were males (71.1\%). Patients aged 51-60 years (23.9\%) constituted the largest age group. The majority came from urban areas $(72.3 \%)$. There were nine deaths in the examined group; those patients were not taken into consideration in the statistical analysis (due to lack of results on the day of discharge and very low, nonsignificant results on the day of admission). The characteristics of the study population are presented in Table 1.

\section{Instruments}

The method used was direct observation and measurement. The assessment was performed twice (assessments 1 and 2) 
Table I Characteristics of the study population

\begin{tabular}{|c|c|}
\hline Variable & n (\%) \\
\hline \multicolumn{2}{|l|}{ Gender } \\
\hline Female & $46(28.9)$ \\
\hline Male & II3 (7I.I) \\
\hline \multicolumn{2}{|l|}{ Age, years ${ }^{\mathrm{a}}$} \\
\hline$\leq 30$ & $22(18.8)$ \\
\hline $31-40$ & $19(11.9)$ \\
\hline $4 I-50$ & $19(11.9)$ \\
\hline $5 I-60$ & $38(23.9)$ \\
\hline $61-70$ & $18(11.3)$ \\
\hline $7 I-80$ & $21(13.2)$ \\
\hline $81-90$ & $22(13.8)$ \\
\hline \multicolumn{2}{|c|}{ Place of residence } \\
\hline Rural & $44(27.7)$ \\
\hline Urban & II 5 (72.3) \\
\hline \multicolumn{2}{|c|}{ Hospitalization period, days } \\
\hline $1-3$ & $42(28.0)$ \\
\hline $4-6$ & $57(38.0)$ \\
\hline $7-10$ & $27(18.0)$ \\
\hline$>10$ & $24(16.0)$ \\
\hline Deaths & $9(5.9)^{*}$ \\
\hline
\end{tabular}

Notes: ${ }^{\text {Mean }}=55.2, \mathrm{SD}=19.99$ and range $=16.0-93.0 . *$ In the main analysis, these patients were not considered due to lack of results on day of discharge and very low nonessential results on day of admission.

Abbreviation: SD, standard deviation.

by a trained team of neurosurgical nurses, including the authors of this study, on their scheduled shifts. The measuring scales applied by the team were standardized tools used worldwide in everyday clinical practice (the GCS and Glasgow Outcome Scale [GOS]) and scales chosen by the authors of the study (FIR and FCS), which are used in Poland.

Although particular measuring tools are similar in construction (eg, FIR and FCS), their practical application in TBI patients needs to be analyzed. The patient's level of consciousness was assessed with the GCS, ${ }^{7}$ where $13-14$ points indicates mild injury, 9-12 points indicates moderate injury, and 3-8 points indicates severe injury. ${ }^{8}$ The level of these disorders were considered as mild (13-15 points), moderate (9-12 points), unconsciousness (6-8 points), decorticate (5 points), and decerebrate (4 points).

Functional capacity was analyzed using two measurement tools, ie, the FCS and the FIR. On the FCS, ${ }^{9,10}$ the deficit of care was classified as: group I, independence; group II, mild dependence; group III, moderate dependence; and group IV, dependence. This scale enables the clinician to recognize the functional abilities of a patient with a particular clinical condition, as well as the patient's dependence on nursing staff. The scale has 12 markers, ie, ambulation (1), alimentation (2), personal hygiene (3), physiological needs (4), life function [GCS] (5), breathing (6), diagnosis (7), preoperative and postoperative treatment (8), dressing and drainage (9), severity of pain (10), pharmacotherapy (11), and neuropsychological outcome (12).

The FIR ${ }^{1}$ categorizes the patient's independence and need for assistance into the following groups: group I, total dependence (the patient requires intensive care); group II, significant dependence (the patient requires significant help); group III, partial dependence (the patient requires some help); and group IV, independence (total self-reliance). FIR is a universal, simple, and easily used tool for assessment of activities of daily living in patients with various neurological and motor system disorders.

A scale used for assessment of the final results is the GOS, ${ }^{11}$ where 5 indicates convalescence, 4 indicates mild disability, 3 indicates serious disability, 2 indicates a permanent vegetative state, and 1 indicates death. GOS assesses the patient's postoperative condition, level of self-reliance, and ability to perform social and professional roles. It is the scale most commonly used for assessment of the outcome of intensive care and for long-term monitoring of the recovery process after head and nervous system injuries. It is a relatively simple measurement tool, is used worldwide, and facilitates comparison between reports, including GOS outcomes.

\section{Ethical approval}

The research protocol was approved by the bioethics committee at Collegium Medicum, Nicolaus Copernicus University, Torun, Poland (291/2013).

\section{Statistical analysis}

A descriptive analysis of the results is presented in tables. Means with standard deviations were calculated. The Spearman's rank correlation coefficient $(R)$ was used to measure dependence between two variables. The non-parametric Mann-Whitney $U$-test was also used. The statistical significance level was set at $P \leq 0.05$. All calculations and figures were prepared using Microsoft Excel and Statistica version 10.0.

\section{Results}

The level of consciousness was assessed using the GCS scale. On the day of hospital admission (assessment 1), the majority of patients $(118,78.7 \%)$ were diagnosed with mild impairment of consciousness (GCS 13-15 points). On the day of discharge (assessment 2) patients with mild impairment of consciousness were the most numerous group $(134,89.3 \%)$. In general, no improvement was observed in 91 patients (Table 2). There was no statistically significant difference in gender, age, place of residence, or results on the GCS scale between the day of admission and the day of discharge $(P>0.05$, Table 2$)$. 
Table 2 Assessment of patients' condition using particular scales

\begin{tabular}{|c|c|c|c|}
\hline \multirow[t]{2}{*}{ Scale } & \multirow[t]{2}{*}{ Groups, determinants, points } & \multirow{2}{*}{$\frac{\text { Assessment I }}{\mathrm{n}(\%)}$} & \multirow{2}{*}{$\begin{array}{l}\text { Assessment } 2 \\
\mathrm{n}(\%)\end{array}$} \\
\hline & & & \\
\hline \multirow[t]{10}{*}{ GCS } & Mild, I3-15 & I I 8 (78.7) & I 34 (89.3) \\
\hline & Moderate, 9-12 & $15(10.0)$ & $7(4.7)$ \\
\hline & Loss of consciousness, $6-8$ & $12(8.0)$ & $7(4.7)$ \\
\hline & Decorticate, 5 & I (0.7) & $\mathrm{I}(0.7)$ \\
\hline & Decerebrate, 4 & $4(2.7)$ & $\mathrm{I}(0.7)$ \\
\hline & Mean & 13.2 & 14.1 \\
\hline & SD & 2.866 & 2.219 \\
\hline & Gender and GCS & $P=0.988$ & $P=0.857$ \\
\hline & Age and GCS & $P=0.577$ & $P=0.772$ \\
\hline & Place of residence and GCS & $P=0.075$ & $P=0.4 \mid 4$ \\
\hline \multirow[t]{9}{*}{ FCS } & I, self-reliant patient & $48(32.0)$ & $112(74.7)$ \\
\hline & II, patient requiring help & $59(39.3)$ & $23(15.3)$ \\
\hline & III, patient requiring much help & $29(19.3)$ & $6(4.0)$ \\
\hline & IV, patient requiring intensive care & $14(9.3)$ & $9(6.0)$ \\
\hline & Mean & 34.1 & 41.8 \\
\hline & SD & 9.855 & 9.414 \\
\hline & Gender and FCS & $P=0.350$ & $P=0.700$ \\
\hline & Age and FCS & $P=0.001$ & $P=0.088$ \\
\hline & Place of residence and FCS & $P=0.310$ & $P=0.318$ \\
\hline \multirow[t]{9}{*}{ FIR } & I, total dependence & $43(28.7)$ & $18(12.0)$ \\
\hline & II, considerable dependence & $42(28.0)$ & $12(8.0)$ \\
\hline & III, partial dependence & $22(14.7)$ & $20(13.3)$ \\
\hline & IV, independence & $43(28.7)$ & $100(66.7)$ \\
\hline & Mean & 61.19 & 85.15 \\
\hline & SD & 31.923 & 28.988 \\
\hline & Gender and FIR & $P=0.388$ & $P=0.185$ \\
\hline & Age and FIR & $P=0.000$ & $P=0.00 \mathrm{I}$ \\
\hline & Place of residence and FIR & $P=0.34 I$ & $P=0.469$ \\
\hline \multirow[t]{9}{*}{ GOS } & 5, patient can lead normal life, convalescence & - & $90(60.0)$ \\
\hline & 4 , mild disability, self-reliant patient & - & $24(16.0)$ \\
\hline & 3, high disability, patient needs help in ADL & - & $27(18.0)$ \\
\hline & 2 , permanent vegetative state & - & $9(6.0)$ \\
\hline & Mean & - & 4.3 \\
\hline & SD & - & 0.968 \\
\hline & Gender and GOS & - & $P=0.267$ \\
\hline & Age and GOS & - & $P=0.000$ \\
\hline & Place of residence and GOS & - & $P=0.660$ \\
\hline
\end{tabular}

Abbreviations: ADL, activities of daily living; FIR, Functional Index "Repty”; GCS, Glasgow Coma Scale; FCS, Functional Capacity Scale; GOS, Glasgow Outcome Scale; $\mathrm{SD}$, standard deviation.

The mean score for functional capacity measured with the FCS was 34.1 points on the day of admission (71.7\%), and 41.8 points $(87.2 \%)$ on the day of discharge. At assessment 1 , the majority of patients $(59,39.3 \%)$ were classified as group II (mildly dependent), with the smallest number of patients $(14,9.3 \%)$ being classified as group IV (dependent). At discharge, most of the patients $(112,74.7 \%)$ were classified as group I (independent) and only six patients $(4.0 \%$, the smallest number of patients) as group III (moderately dependent). Analyzing the relationship between these results and demographic factors, a significant dependence was found between patient age and functional capacity on the day of admission $(P=0.001)$. The data are presented in Table 2 .

Using the FIR on the day of admission, 43 patients (28.7\%) were classified as group I (totally dependent). The same number of patients $(43,28.7 \%)$ were classified as group IV (independent). The smallest number of patients (22, $14.7 \%$ ) were classified as group III (partially dependent). On the day of discharge, the majority of patients $(100,66.7 \%)$ were classified as group IV (independent), while the smallest number of patients $(12,8.0 \%)$ were classified as group II (highly dependent). A small but significant correlation was observed between age and outcome on the FIR on days of admission $(P=0.000)$ and discharge $(P=0.001$, Table 2$)$.

The final results of treatment were assessed using the GOS, which showed that $60 \%$ of patients had recovered from their injury and were able to live normally. Nine patients remained in a vegetative state. We also found a significant correlation between the results of treatment measured with this scale and patient age $(P=0.000$, Table 2$)$. 
Table 3 Dependence between GCS and FCS

\begin{tabular}{|c|c|c|c|c|}
\hline \multirow[t]{3}{*}{ Assessment } & \multicolumn{4}{|l|}{ FCS } \\
\hline & I & II & III & IV \\
\hline & n (\%) & n (\%) & n (\%) & n (\%) \\
\hline \multicolumn{5}{|c|}{ Assessment I: GCS, points } \\
\hline $13-15$ & $48(100.0)$ & $55(93.2)$ & $15(5 \mid .8)$ & $0(0.0)$ \\
\hline $9-12$ & $0(0.0)$ & $4(6.8)$ & $9(3 \mid .0)$ & $4(28.6)$ \\
\hline $6-8$ & $0(0.0)$ & $0(0.0)$ & $5(17.2)$ & $9(64.3)$ \\
\hline 5 & $0(0.0)$ & $0(0.0)$ & $0(0.0)$ & I (7.I) \\
\hline \multirow[t]{2}{*}{4} & $0(0.0)$ & $0(0.0)$ & $0(0.0)$ & $0(0.0)$ \\
\hline & \multicolumn{4}{|c|}{$\mathrm{n}=150, R=-0.652 \mathrm{t}(\mathrm{n}-2)=-10.460, P=0.00$} \\
\hline \multicolumn{5}{|c|}{ Assessment 2: GCS, points } \\
\hline $13-15$ & $112(100.0)$ & $21(91.3)$ & I (I6.7) & $0(0.0)$ \\
\hline $9-12$ & $0(0.0)$ & $2(8.7)$ & $3(50.0)$ & $2(22.2)$ \\
\hline $6-8$ & $0(0.0)$ & $0(0.0)$ & $2(33.3)$ & $5(55.6)$ \\
\hline 5 & $0(0.0)$ & $0(0.0)$ & $0(0.0)$ & $1(11.1)$ \\
\hline \multirow[t]{2}{*}{4} & $0(0.0)$ & $0(0.0)$ & $0(0.0)$ & $\mathrm{I}(\mathrm{II} . \mathrm{I})$ \\
\hline & \multicolumn{4}{|c|}{$\mathrm{n}=150, R=-0.687, \mathrm{t}(\mathrm{n}-2)=-10.486, P=0.00$} \\
\hline
\end{tabular}

Abbreviations: FCS, Functional Capacity Scale; GCS, Glasgow Coma Scale.

On the day of admission, it was observed that all independent and self-reliant patients (FCS group I) had mild impairment of consciousness (GCS 13-15 points). Mildly dependent patients $(4,6.8 \%)$, classified as FCS group II, had moderate impairment of consciousness (GCS 9-12 points). Similarly, on the day of hospital discharge, patients who were independent in their everyday activities of living scored 13-15 points on the GCS scale. None of the patients who were dependent on others had mild impairment of consciousness. These results were statistically significant ( $P=0.00$, Table 3$)$.

A moderate correlation was found between the results obtained using the GCS and assessment of functional capacity measured with the FIR, both on the day of hospital admission [Spearman's correlation coefficient $R$ $(\mathrm{n}=150, \mathrm{t}(\mathrm{n}-2)=7.612=0.530 ; P=0.00]$ and on the day of discharge [Spearman's correlation coefficient $R(\mathrm{n}=150$, $\mathrm{t}(\mathrm{n}-2)=8.998=0.595 ; P=0.00$, Table 4]. This means that a lower level of consciousness (on the GCS) results in the patient having decreased functional capacity (on the FIR).

A high correlation was found between the scales used for assessment of functional capacity, ie, the FCS and FIR ( $R=-0.854$ at assessment 1 and $R=-0.840$ in assessment 2) which may reflect the similarities between these scales in terms of their scope of construction and application (Table 5).

\section{Discussion}

Disorders of consciousness are a serious complication of TBI. The most common and widespread tool used for their assessment is the GCS which has been shown in the literature to have high reliability and good prognostic ability. ${ }^{12}$

Table 4 Dependence between GCS and FIR

\begin{tabular}{|c|c|c|c|c|}
\hline \multirow[t]{3}{*}{ Assessment } & \multicolumn{4}{|l|}{ FIR } \\
\hline & I & II & III & IV \\
\hline & n (\%) & n (\%) & n (\%) & n (\%) \\
\hline \multicolumn{5}{|c|}{ Assessment I: GCS, points } \\
\hline $13-15$ & $18(4 \mid .8)$ & $37(88.1)$ & $20(91.0)$ & $43(100.0)$ \\
\hline $9-12$ & $10(23.3)$ & $4(9.5)$ & I (4.5) & $0(0.0)$ \\
\hline $6-8$ & $10(23.3)$ & I (2.4) & I (4.5) & $0(0.0)$ \\
\hline 5 & I (2.3) & $0(0.0)$ & $0(0.0)$ & $0(0.0)$ \\
\hline \multirow[t]{2}{*}{4} & $4(9.3)$ & $0(0.0)$ & $0(0.0)$ & $0(0.0)$ \\
\hline & \multicolumn{4}{|c|}{$\mathrm{n}=150, R=0.530 \mathrm{t}(\mathrm{n}-2)=7.612, P=0.00$} \\
\hline \multicolumn{5}{|c|}{ Assessment 2: GCS, points } \\
\hline $13-15$ & $5(27.8)$ & $10(83.3)$ & $19(95.0)$ & $100(100.0)$ \\
\hline $9-12$ & $4(22.2)$ & $2(16.7)$ & I $(5.0)$ & $0(0.0)$ \\
\hline $6-8$ & $7(38.8)$ & $0(0.0)$ & $0(0.0)$ & $0(0.0)$ \\
\hline 5 & $I(5.6)$ & $0(0.0)$ & $0(0.0)$ & $0(0.0)$ \\
\hline \multirow[t]{2}{*}{$13-15$} & I (5.6) & $0(0.0)$ & $0(0.0)$ & $0(0.0)$ \\
\hline & \multicolumn{4}{|c|}{$\mathrm{n}=150, R=0.595 \mathrm{t}(\mathrm{n}-2)=8.998, P=0.00$} \\
\hline
\end{tabular}

Abbreviations: FIR, Functional Index "Repty”; GCS, Glasgow Coma Scale. 
Table 5 Dependence between FCS and FIR

\begin{tabular}{|c|c|c|c|c|}
\hline \multirow[t]{3}{*}{ Assessment } & \multicolumn{4}{|l|}{ FIR } \\
\hline & $\mathbf{I}$ & II & III & IV \\
\hline & n (\%) & n (\%) & n (\%) & n (\%) \\
\hline \multicolumn{5}{|c|}{ Assessment I: FCS } \\
\hline I & $0(0.0)$ & $2(4.8)$ & $4(18.2)$ & $42(97.7)$ \\
\hline II & $10(23.3)$ & $32(76.2)$ & $16(72.7)$ & I (2.3) \\
\hline III & $19(44.2)$ & $8(19.0)$ & $2(9.1)$ & $0(0.0)$ \\
\hline \multirow[t]{2}{*}{ IV } & $14(32.5)$ & $0(0.0)$ & $0(0.0)$ & $0(0.0)$ \\
\hline & \multicolumn{4}{|c|}{$\mathrm{n}=|50, R=-0.854 \mathrm{t}(\mathrm{n}-2)=-19.99|, P=0.00$} \\
\hline \multicolumn{5}{|c|}{ Assessment 2: FCS } \\
\hline I & $0(0.0)$ & $0(0.0)$ & $14(70.0)$ & $98(98.0)$ \\
\hline II & $6(33.3)$ & $9(75.0)$ & $6(30.0)$ & $2(2.0)$ \\
\hline III & $3(16.7)$ & $3(25.0)$ & $0(0.0)$ & $0(0.0)$ \\
\hline \multirow[t]{2}{*}{ IV } & $9(50.0)$ & $0(0.0)$ & $0(0.0)$ & $0(0.0)$ \\
\hline & \multicolumn{4}{|c|}{$\mathrm{n}=150, R=-0.840 \mathrm{t}(\mathrm{n}-2)=-18.852, P=0.00$} \\
\hline
\end{tabular}

Abbreviations: FCS, Functional Capacity Scale; FIR, Functional Index "Repty”.

The highest mortality and disability rates are found in patients with severe TBI. ${ }^{13}$ Mortality in our study population was $5.7 \%$, and $11 \%$ had severe injuries (GCS 3-8 points). In our study, TBI was more common in men (71\%) than in women (29\%), which is consistent with data reported from other countries. ${ }^{5,13-15}$ Although TBI is most common in people under the age of 40 years, ${ }^{5,15,16}$ this age group represented only $26 \%$ of all subjects included in our study.

The literature indicates that about $50 \%$ of patients who suffer a serious TBI have moderate or high levels of disability, as evaluated by the GOS. ${ }^{17}$ In our study, these patients constituted $24 \%$ of the study population.

The survival rate after TBI and in the disabled patient population as a whole depends mostly on the degree of the patient's problems with immobilization, urinary and fecal incontinence, dysphagia, early epilepsy, and loss of cognitive and intellectual functioning. ${ }^{1}$ In light of these problems, it is important to assess the patient's functional capacity. The tools used in our study for functional assessment were the FCS and FIR. The results show that about $42 \%$ of patients required considerable or intensive help with activities of daily living on the day of hospital admission. On the day of discharge, only $15 \%$ required this level of assistance. Review of the literature indicates that limited ability resulting from moderate or severe injury, at least a year after hospitalization, occurs in up to $50 \%$ of individuals. Fifteen percent of patients need constant assistance. ${ }^{18}$ It should be emphasized that these results correlate with age, ie, the older the patient, the more significant the functional limitations. This finding is consistent with studies reported by other authors. ${ }^{19}$ According to Gardner et $\mathrm{al}^{20}$ advanced age is an independent variable that determines the worst prognosis after a severe TBI. Potts et al $^{21}$ divided patients into four age groups, ie, <35, 35-49, 50-64, and $\geq 65$ years, and reported a mortality rate in each group of $19.2 \%, 66.7 \%, 60 \%$, and $80 \%$, respectively, and no significant correlation was found between age and GOS score ( $r=-0.42 ; P<0.0001)$; however, patients under 35 years of age had higher GOS scores than patients in the other age groups $(P<0.0001)$.

Descriptions of scales for assessment of functional capacity in TBI patients are found in numerous publications. ${ }^{18,19,22}$ The authors of this study found a significant dependence between the FCS and FIR, which may reflect the similarities between these tools in terms of their scope of construction and application.

Functional ability and quality of life in TBI patients can also be influenced by a degree of impaired consciousness, ${ }^{23,24}$ as shown by our study. A correlation between GCS and FCS was found as well as a relationship between GCS and FIR. Settervall et al ${ }^{25}$ found a correlation between GCS and some domains of the Short Form-36, and the highest result was obtained for functional capacity.

\section{Conclusion}

The majority of patients in our study population suffered from mild impairment of consciousness. However, on the day of discharge, $10 \%$ (measured with the FCS) and 20\% (measured with the FIR) of our study patients required considerable or intensive help with activities of daily living. A moderate correlation was found between the GCS and the scales for assessment of activities of daily living, ie, the FCS and FIR. A high correlation was found between the FCS and FIR, which may result from the similarities between these scales in their scope of construction and application. Correlations between particular scales do not indicate which measuring 
instrument is the best. However, it may be concluded that they can all be successfully applied in neuro-nursing practice. Our results highlight the need for such analysis to facilitate planning of complex nursing care, implementation of the neurorehabilitation process, and engagement of social services. They also underscore the need for an interdisciplinary team to ensure the best quality of life in TBI patients.

\section{Acknowledgments}

Scientific activity of the Clinical Nursing Department, Collegium Medicum, Nicolaus Copernicus University, Torun, Poland (grant 953/2014). The authors would like to thank those who have contributed to this research. In particular, they are grateful to the nurses in the process of data collection, and to Roksana Rybicka, Senior Lecturer in the Applied Linguistics Department, for her support and valuable suggestions.

\section{Disclosure}

The authors report no conflicts of interest in this work.

\section{References}

1. Opara J, Małecka I, Szczygieł M. Clinimetric measurement in traumatic brain injuries. J Med Life. 2014;7:124-127.

2. Ciesielska N, Sokołowski R, Kędziora-Kornatowska K, et al. Screening clinimetric scales used in the diagnostics of cognitive functions impairment in dementia. Systematic overview. Journal of Health Sciences. 2013;3: 393-410.

3. Wilmowska-Pietruszyńska A, Bilski D. [ICF as a tool for quantitative assessment of violation of proficiency in adjudication for the need of social protection]. Orzecznictwo Lekarskie. 2010;7:1-3. Polish.

4. Cardarelli R, Virgilio R, Taylor L. Evidence-based medicine. Part 2. An introduction to critical appraisal of articles on therapy. J Am Osteopath Assoc. 2007; 107:299-303.

5. Rutkowska M. [Traumatic brain injuries - the XXI century epidemic]. Medycyna Ogólna. 2010;16:192-200. Polish.

6. Wilde EA, McCauley SR, Kelly TM, et al. Feasibility of the Neurological Outcome Scale for Traumatic Brain Injury (NOS-TBI) in Adults. J Neurotrauma. 2010;27:975-981.

7. Teasdale G, Jennett B. Assessment of coma and impaired consciousness. A practical scale. Lancet. 1974;2:81-84.
8. Kaźmierczak K, Majchrzycki M, Stryła W. [The schedule of recommended operations in the rehabilitation of patients after traumatic brain injury with reference to the degree of the injury measured with the Glasgow Coma Scale]. Nowiny Lek. 2011;80:288-294. Polish.

9. Ślusarz R. [Functional Capacity Scale (FCS) in nursing practice]. Journal of Neurological and Neurosurgical Nursing. 2012;1(1):35-40. Polish.

10. Ślusarz R, Biercewicz M, Rybicka R. Functional Capacity Scale in assessment of patients with intracranial aneurysms: reliability and validity. J Neurosci Nurs. 2014;46:46-54.

11. Jennett B, Bond M. Assessment of outcome after severe brain damage: a practical scale. Lancet. 1975;1:480-484.

12. Narayan RK, Michel ME, Ansell B, et al. Clinical trials in head injury. J Neurotrauma. 2002;19:503-557.

13. Jagnoor J, Cameron ID. Traumatic brain injury - support for injured people and their careers. Aust Fam Physician. 2014;43:758-763.

14. Engberg AW, Teasdale TW. [Epidemiology and treatment of head injuries in Denmark 1994-2002, illustrated with hospital statistics]. Ugeskr Laeger. 2007;169:199-203. Danish.

15. Kleiven SP, Peloso M, von Holst H. The epidemiology of head injuries in Sweden from 1987 to 2000. Inj Control Saf Promot. 2003;10:173-180.

16. Pappachan B, Alexander M. Correlating facial fractures and cranial injuries. J Oral Maxillofac Surg. 2006;64:1023-1029.

17. Moppett IK. Traumatic brain injury: assessment, resuscitation and early management. Br J Anaesth. 2007;99:18-31.

18. Berger E, Leven F, Pirente N, Bouillon B, Neugebauer E. Quality of life after traumatic brain injury: a systematic review of the literature. Restor Neurol Neurosci. 1999;14:93-102.

19. Cipolle MD, Geffe K, Getchell J, et al. Long-term outcome in elderly patients after operation for traumatic intracranial hemorrhage. Del Med J. 2014;86:237-244.

20. Gardner RC, Burke JF, Nettiksimmons J, Kaup A, Barnes DE, Yaffe K. Dementia risk after traumatic brain injury vs nonbrain trauma: the role of age and severity. JAMA Neurol. 2014;71:1490-1497.

21. Potts MB, Chi JH, Meeker M, Holland MC, Hemphill JH III, Manley GT. Predictive values of age and the Glasgow Coma Scale in traumatic brain injury patients treated with decompressive craniectomy. Acta Neurochir Suppl. 2008;102:109-112.

22. Hanks RA, Rapport L, Vangel S. Caregiving appraisal after traumatic brain injury: the effects of functional status, coping style, social support and family functioning. Neuro Rehabilitation. 2007;22:43-52.

23. Tasaki O, Shiozaki T, Hamasaki T, et al. Prognostic indicators and outcome prediction model for severe traumatic brain injury. J Trauma. 2009;66:304-308.

24. Joosse P, Smit G, Arendshorst RJ, Soedarmo S, Ponsen KJ, Goslings JC. Outcome and prognostic factors of traumatic brain injury: a prospective evaluation in a Jakarta University hospital. J Clin Neurosci. 2009; 16:925-928.

25. Settervall CH, Cardoso de Sousa RM. [Glasgow Coma Scale and quality of life after traumatic brain injury]. Acta Paul Enferm. 2012;25: 364-370. Portuguese.
Patient Preference and Adherence

\section{Publish your work in this journal}

Patient Preference and Adherence is an international, peer-reviewed, open access journal that focuses on the growing importance of patient preference and adherence throughout the therapeutic continuum. Patient satisfaction, acceptability, quality of life, compliance, persistence and their role in developing new therapeutic modalities and compounds to optimize

\section{Dovepress}

clinical outcomes for existing disease states are major areas of interest for the journal. This journal has been accepted for indexing on PubMed Central. The manuscript management system is completely online and includes a very quick and fair peer-review system, which is all easy to use. Visit http://www. dovepress.com/testimonials.php to read real quotes from published authors. 